\title{
PARQUE CONTEMPORÂNEO DE CUNHO ECOLÓGICO, COM CARACTERIZAÇÃO DE ECOGÊNESE
}

\author{
THE CONTEMPORARY PARK - AN ECOGENESIS APPROACH
}

\author{
LOPES, Débora Tognozzi \\ GUIMARÃES, Lucia do Nascimento \\ E-mail: detognozzi@yahoo.com.br
}

\section{RESUMO}

Este projeto de pesquisa consiste em uma série de medidas que visam conservar e recuperar ambientalmente um trecho da área de várzea do rio Paraíba do Sul - especificamente a área adjacente ao campus da Universidade do Vale do Paraíba no limite dos municípios de Jacareí e São José dos Campos, SP. O projeto irá focar a restauração da vegetação original e a criação de um parque ecológico na área, que foi sujeita a extração ilegal de areia do rio ao longo da década passada. Propostas de modificações na lei de zoneamento, e aplicação dos instrumentos previstos no Estatuto da Cidade cabíveis, deverão ser utilizados no desenvolvimento, visando atingir os ojbetivos do projeto.

Palavras-chave: Paisagismo, ecogênese, parque ecológico, sustentabilidade, manejo ambiental, ecossistema de várzea, zoobotânico.

\begin{abstract}
This research project consists in a series of measures aiming at the environmental protection and restoration of a swamp area along the Paraiba do Sul river, nearby the campus of the Vale do Paraiba University and the border between the cities of Sao Jose dos Campos and Jacarei, in the state of Sao Paulo. The project will focus on the restoration of the original vegetation and the creation of an ecological park in the area which was subject to illegal extraction of river sand along the past decade. Proposals of modifications to the city zoning and the applicable instruments foreseen in the City Statute shall be used as tools in developing and accomplishing the objectives of the project.
\end{abstract}

Key words: Landscape, ecosystem, marsh, sustentability.

\section{Introdução}

O mote deste estudo reside na urgência de se apresentar alternativas de intervenção para recuperação para a área degradada nas margens do rio Paraíba do Sul, no limite dos municípios de Jacareí e São José dos Campos, região conurbada do Vale do Paraíba, estado de São Paulo. Tal área foi degradada com a extração ilegal de areia na década de 1990, dando origem a cavas - lago artificial - deixando o solo exposto e promovendo o assoreamento do leito do rio Paraíba do Sul. A degradação foi tal que, além de a flora ter sido totalmente danificada, a fauna que dela sobrevivia foi extinta ou migrou. Hoje há um trabalho de reaproveitamento destas cavas para criação de peixes, que visa a alimentação de estudantes da rede pública, promovido pelo NEPLI (Núcleo de Estudos em Piscicultura, Limnologia e Ictiologia). A Prefeitura do campus da UNIVAP promove um trabalho na tentativa de recuperação da flora na "área de cavas", com base em EIA-RIMA. Esta obra, contudo, tem-se mostrado incipiente, sem levar em conta a degradação do solo, e as espécies nativas adequadas, bem como o modo mais adequado de reintegrá-las ao seu ambiente de origem. 
A proposta tem como meta os seguintes aspectos, buscando, a médio e longo prazo, atingir um cenário de sustentabilidade.

Pretende-se conseguir a conservação e proteção dos recursos naturais e culturais da área compreendida às margens do Rio Paraíba do Sul na divisa dos municípios de São José dos Campos e Jacareí, em terreno pertencente à Universidade do Vale do Paraíba, próximo à rodovia Presidente Dutra.

Ecogênese: neologismo que tem como significado "o processo de restauração de um ecossistema degradado, restituindo-lhe as condições mais próximas das originais" (CHACEL, 2005).

São José dos Campos e Jacareí, em terreno pertencente à Universidade do Vale do Paraíba, próximo à rodovia Presidente Dutra.

Visa-se produzir um ambiente paisagístico que culmine num Parque Intermunicipal, baseado no conceito de Ecogênese na região do Vale do Paraíba, com acesso pela rodovia Presidente Dutra (Jacareí) e pelo bairro da Urbanova (São José dos Campos).

Pretende-se atingir a ampliação, de forma racional, dos interesses sociais na região, promovendo um ambiente de desenvolvimento cultural, científico e de lazer.

Busca-se a promoção do desenvolvimento auto-sustentável, com inclusão social da comunidade camponesa e ribeirinha da área de estudo.

\section{Contextualização}

Em 1972, em Estocolmo, representantes de vários países do mundo reúnem-se para discutir a sanidade do planeta. É então que surge a idéia de desenvolvimento sustentável. Aparecem em vários páíses, com diferentes graus de eficácia ou comprometimento, Políticas Nacionais de Meio Ambiente. Em 1973, o Governo Federal do Brasil cria a Secretaria de Meio Ambiente em Brasília. Com a Resolução do Conselho Nacional do Meio Ambiente - Conama 001 de 1986, tornava-se obrigatória no país a realização dos Estudos de Impactos Ambientais (EIA) e Relatório de Impacto de Meio Ambiente (RIMA).

\section{Fundamentação teórica}

A área de estudo é parte de um "banhado", bioma que refere-se a uma extensa planície, formada por sedimentação, na várzea do rio Paraíba do Sul que, historicamente foi destinada às atividades de pastoreio e cultivo agrícola de arrozais. No trecho em questão, uma pequena comunidade de população ribeirinha foi dando lugar a novas invasões, desta vez por populações urbanas.

Como se sabe, legislações muito rígidas dão margem a fraudes (FRANCO, 2004). E é dentro deste pensamento que entendemos que, ao invés de impor uma proibição rigorosa de ocupação de tal área, venhamos a tentar regularizar sua implantação de forma racional e sustentável. Ainda seguindo este raciocínio, ambientalistas conceituados como aqueles ligados ao NEPAUB-USP e ao NEPAM-Unicamp, defendem a postura de não-expulsão das populações tradicionais das áreas de proteção ambiental, tendo em vista sua possibilidade de efetuar o manejo sustentável dos recursos naturais na área em que residem. Tal raciocínio vem dar suporte maior à postura de não afastamento desta população do local, mas apenas uma readequação de sua moradia, às necessidades ambientais e urbanísticas (DIEGUES, 2003).

A várzea é um dos ecossistemas mais ricos da bacia do rio Paraíba do Sul. No entanto, a várzea, de modo geral, é um ecossistema ameaçado.

Este projeto consiste em medidas que visam preservar ambientalmente a área de várzea do rio Paraíba do Sul no trecho indicado, buscando recuperar a vegetação nativa, dando a ela uma destinação de uso, como parque. 
Como diz Del Rio (1990), áreas próximas às massas de água são, consensualmente, tidas como aprazíveis pelo homem, e devem, por esta razão, ser aproveitadas como áreas destinadas ao lazer e à recreação. Por esta razão, incluímos neste projeto o fator de uso desta área pelas populações das duas cidades limítrofes, com o fim de que sintam-se responsáveis pela recuperação da mesma, numa gestão participativa, com a implantação de atividades para Educação Ambiental, dirigidas de acordo com faixas etárias, nos parâmetros dos atuais parques zoobotânicos, concebendo a biota como um todo.

A missão institucional primária dos parques zoobotânicos é o desenvolvimento de projetos de pesquisa e extensão ambientais. Esta área visa servir como laboratório natural para estudos ambientais e ecológicos, assim como refúgio para pequenos animais e abrigo da flora natural deste ecossistema.

Uma maneira de se conservar determinada área, mormente uma área de interesse ambiental, como é o caso, é dar a ela uma destinação de uso (FRANCO, 2004). Pois somente quando uma população utiliza uma área é que passa a dedicar-lhe cuidados de manutenção; desta forma evita-se a degradação pelo abandono ou uso inadequado da mesma. No entanto, mais que conservar, nossa intenção é intervir na área em questão, não projetando na natureza, mas projetando com a natureza (MAC HARG, 1960).

É conhecida a experiência de Fernando Chacel na recuperação da vegetação ciliar da Lagoa da Tijuca na cidade do Rio de Janeiro. Sua pesquisa de paisagismo e ecogênese levou-o a resgatar a vegetação nativa e criar um parque aprazível e bem modelado a partir de espécies inusitadas.

O processo de ecogênese visa compensar, de forma biótica, os impactos atuais causados por intervenções de natureza não conservacionista (cavas de areia) já realizadas, e as que se farão sentir após futuros impactos (vias de acesso a serem projetadas, e infra-estrutura do parque, tais como sede, lanchonete, banheiros e centros de pesquisa, observatório, etc.).

De modo semelhante à tarefa realizada por Chacel, pensamos em projetar paisagens aprazíveis e de valor estético com as espécies nativas próprias do ecossistema de várzea em regiões de mata tropical. O plantio de espécies nativas é o primeiro passo para evitar ocupações com atividades não compatíveis com a vocação de zona de conservação de vida silvestre. Sabemos, contudo que, para tanto, se faz necessário um tratamento inicial do terreno, o que se obtém a partir do plantio de espécies que recuperem seu substrato nutritivo, tais como leguminosas. Um segundo passo seria o plantio de espécies pioneiras para, em seguida, adaptar as espécies que aí habitavam quando da sua degradação. Busca-se, deste modo, fundir o natural e o plantado em uma unidade paisagística representativa dos ecossistemas do local.

Não podemos deixar de citar aqui o trabalho infatigável e a contribuição inestimável para o uso da vegetação nativa em projetos de paisagismo de Roberto Burle Marx, do qual Chacel foi discípulo. O interesse pela variedade de espécies, formas e cores das plantas nativas brasileiras é despertado em Roberto Burle Marx quando começa a colecionar e buscar entender o cultivo, enxertia, hábitos e reprodução de cada espécie. A exuberância de cores e formas do seu jardim são sua marca registrada, assim como a forma de tratamento que dá a plantas, antes nunca usadas em paisagismo.

Segundo Palazzo e Both (1993), a vegetação nativa pode e deve ser tratada como vegetação ornamental. E é desta forma que compreendemos o trabalho de Chacel com vegetação de mangue e restinga nas margens da lagoa da Tijuca. De modo semelhante, propomos a criação de um parque aprazível e bem modelado a partir de espécies inusitadas: as espécies nativas da área de várzea da bacia do rio Paraíba do Sul. 


\section{Justificativa}

Considerando a vasta área em torno da vargem do rio Paraíba do Sul e região das cavas de areia, achamos imperativo fazer um levantamento das áreas de interesse ambiental - áreas degradadas em função da extração irregular de areia - que poderão tornar-se de interesse científico, transformando-as em roteiros culturais para estudantes em todos os níveis e também criando elementos para o turismo ecológico. O progresso das cidades não pode mais continuar implicando em impactos ambientais de tal ordem, que deixem atrás de si rastros de polvição e destruição. Apesar da especulação imobiliária, ainda existem setores nos municípios de Jacareí e São José dos Campos, que permanecem em bom estado de conservação (APAs). Trata-se de um patrimônio deixado pelos nossos ancestrais que pretendemos legar às futuras gerações.

\section{Objetivos}

\section{Objetivo geral}

Gerar informações de qualidade e quantidade suficientes para, em conjunto com uma equipe multidisciplinar, subsidiar a elaboração de projeto para um parque de cunho ecológico, com acessos alternativos, visando a conservação e a utilização, por parte das populações das cidades de São José dos Campos e Jacareí, bem como núcleo de pesquisas ambientais e programação de visitas monitoradas.

\section{Objetivos específicos}

1) Avaliação das informações existentes para identificar lacunas do conhecimento e espécieschave da várzea.

2) Análise de dados sobre a área da várzea e das cavas na região estudada.

3) Coleta de dados sócio-ambientais e histórico-culturais junto a entidades e à comunidade visando informatizá-los.

4) Integrar instituições de pesquisas científicas e órgãos do Governo Municipal, Estadual e Federal que atuam no Meio Ambiente e no Patrimônio Cultural.

5) Criar condições de sustentabilidade, ampliando-se os setores de interesse acadêmico e turístico.

6) Promover a recuperação ambiental da área degradada e o resgate arqueológico de sítios com vestígios da cultura indígena presentes na área estudada, contando com o apoio das diversas disciplinas.

7) Planejar e implementar atividades voltadas para a Educação Ambiental, dirigidas de acordo com as faixas etárias.

8) Planejar a produção de áudio-visuais, estabelecer prioridades e programar visitas dirigidas.

9) Integração e projeção das informações obtidas.

\section{Base metodológica}

Informar aos analistas do projeto de forma clara, verdadeira e inequívoca, a real situação presente da área de intervenção, assim como as propostas viárias e paisagísticas utilizadas ao longo do parque:

I) Levantamento topográfico (declividades, drenagem superficial);

II) levantamento fotográfico(fotos in loco, fotos aéreas);

III) levantamento dos tipos de solo (permeabilidade do solo, sustentabilidade do solo, geomorfologia, suscetibilidade a erosão);

IV) levantamento das características da vegetação atual; 
V) levantamento das vias de acesso atuais;

VI) projeto viário/aspectos legais/invasões ilegais/vegetações;

VII) valores sociais e ambientais (valores econômicos do solo da região de interesse: áreas inundáveis, valores históricos, cênicos, interativos, hídricos, florestais; valores ambientais da área de interesse: fauna e flora, valores residenciais, e institucionais);

VIII) projeto paisagístico: arranjo geral; e arranjos setoriais;

IX) perspectiva.

\section{Relevância}

A várzea é um dos ecossistemas mais ricos da bacia do rio Paraíba do Sul. No entanto a várzea, de modo geral, é um ecossistema ameaçado e as principais causas deste processo de degradação são: gestão ineficiente, falta de políticas específicas para promover o desenvolvimento sustentável, fiscalização incipiente, entre outros. Embora haja vários estudos básicos sobre a ecologia de várzea (estrutura, funcionamento e biodiversidade), há uma escassez de estudos aplicados a sistemas de manejo efetivos. As políticas públicas elaboradas para este tipo de ambiente têm negligenciado a especificidade do ecossistema de várzea, mostrando-se, em geral excessivamente genéricas.

\section{Contribuição à sociedade}

A população carece de mais e maiores parques de lazer e recreio em ambos os municípios atingidos.

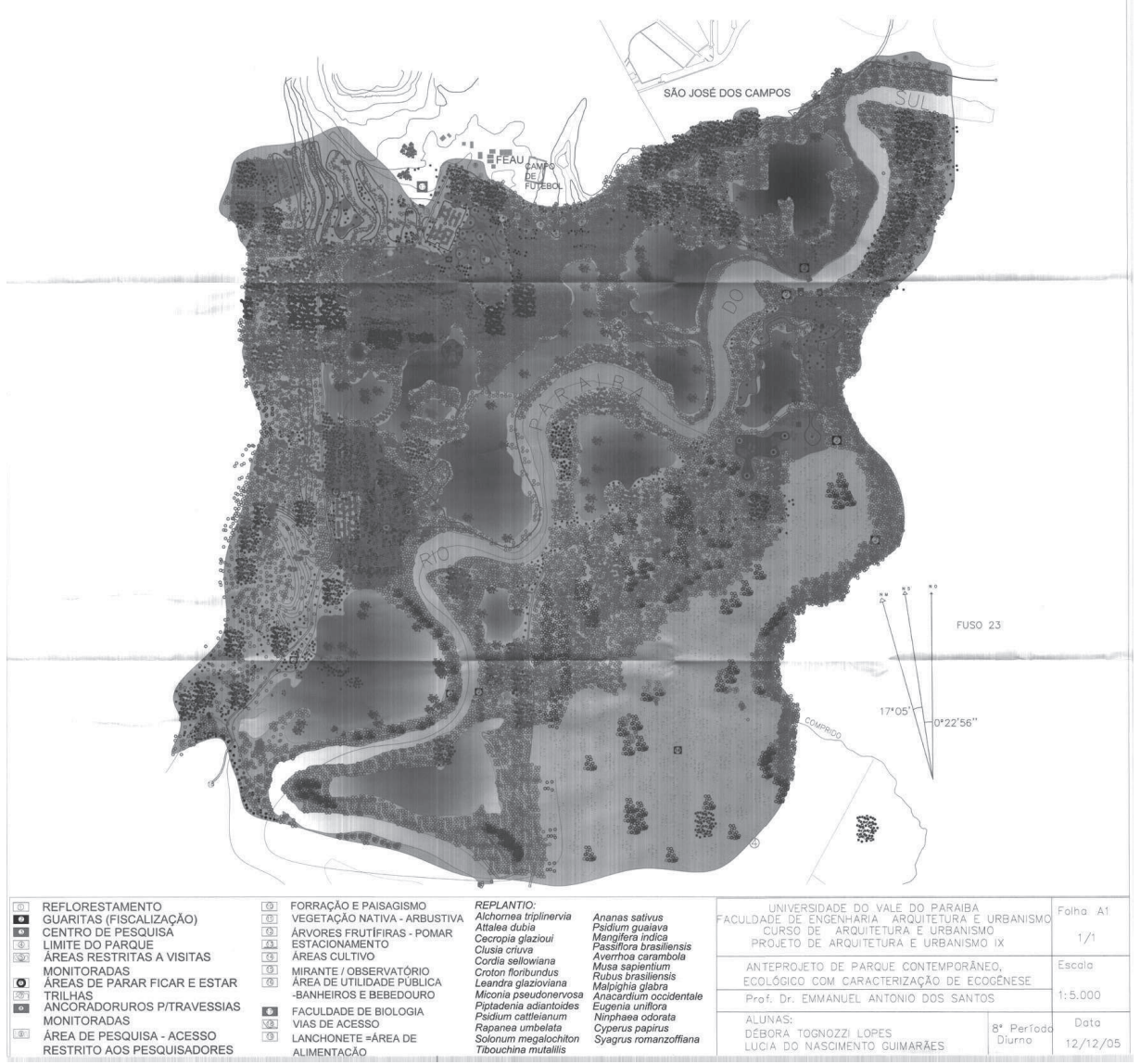


A educação ambiental que aí se promoverá, resultará, em médio e longo prazo, em benefícios para a própria população.

A restauração da área degradada reverterá em benefício para toda a população ribeirinha do vale do rio Paraíba do Sul - nisto incluídos todos os municípios que desta bacia se beneficiam.

A criação de um núcleo de estudos ambientais enriquecerá o programa de educação ambiental das comunidades atingidas.

\section{Bibliografia}

ALMEIDA, J. R.; MORAES, F. E.; SOUZA, J. M.; MALHEIROS, T. M. Planejamento ambiental para participação da gestão ambiental para nosso futuro comum: Uma necessidade, um desafio. 2. ed., Rio de Janeiro: CEPAM/Thex Editora, 1999.

CHACEL, Fernando Magalhães. Paisagismo e ecogênese. Rio de Janeiro: Fraiha, 2001.

DEL RIO, Vicente. Desenho urbano. Rio de Janeiro: Ed. Guanabara, 1990.

DIEGUES, Antônio Carlos Santana. O mito moderno da natureza intocada. 3. ed. São Paulo: Hucitec/Núcleo de Apoio à Pesquisa sobre Populações Humanas e Áreas Úmidas Brasileiras, USP, 2000.

FRANCO, Maria Assunção Ribeiro. Desenho ambiental: Uma introdução à arquitetura da paisagem com paradigma ecológico. São Paulo: Anablume, 2004.

KLIASS, Rosa G. Parques urbanos de São Paulo. São Paulo: Pini, 1993.

MACEDO, Silvio Soares. Roberto Burle Marx and the founding of modern brazilian landscape architecture. In: VACCARINO, R. (E). Roberto Burle Marx. Landscape reflected. Nova York: Princeton Architectural Press, 2000.

MACEDO, Silvio Soares; SAKATA, Francine Gramacho. Parques urbanos no Brasil. São Paulo: Edusp/Imprensa Oficial do Estado, 2002 (Coleção Quapá).

MAGALHÃES, L. E. A questão ambiental. São Paulo: Terragraph, 1994.

MC HARG, lan. Projetar com a natureza. Boston: MIT, 1965.

MIRANDA, Danilo Santos de. (Org.) O parque e a arquitetura - Uma proposta lúdica. Campinas-SP: Papirus, 1996 (Coleção Fazer/Ler).

ODUM, Eugene P. Ecologia. Rio de Janeiro: Ed. Guanabara, 1983.

PALAZZO JR., José Truda; BOTH, Maria do Carmo. Flora ornamental brasileira: Um guia para o paisagismo ecológico. Porto Alegre: Sagra: DC Luzzatto, 1993.

REVISTA PROJETO DESIGN, n. 305, jul. 2005. Entrevista Por Evelise Grunow e Fernando Serapião.

ROMERO, M. A. B. Princípios bioclimáticos para desenho urbano. São Paulo: P. W., 1988.

RUANO, Miguel. Ecourbanismo: Entornos humanos sustentáveis: 60 projetos. Barcelona: Gustavo Gilli, 1999.

SANTOS, Milton. A urbanização brasileira. São Paulo: Hucitec, 1993.

SITES:

CHACEL, 2005: www.vitruvius.com.br/resenhas/textos/resenha005.asp- 02/12/2005;

http://www.geocities.com/apisaniello-05/10/2005;

htpp://www.wmtambiental.com.br-05/10/2005;

htpp://www.artliber.com.br/paisagismo.htm- 02/12/2005;

htpp://www.revistasim.com.br/asp/materia.asp?idtexto=1250 -05/12/2005;

http://www.sefaz.es.gov.br/painel/BMBiol2.htm - 12/03/2006;

htpp://www.ufac.br/orgaosup/pz/index.htm - 34k - 12/03/2006;

www.ead.fea.usp.br/cad-pesq/arquivos/uniformizacao_artigos.pdf-12/03/2006. 